\title{
Determinación serológica de leucosis bovina enzoótica en novillas de levante y vacas adultas de la vereda Morichal, Yopal, Casanare
}

\author{
Serological determination of enzootic bovine leukosis \\ in raise heifers and adult cows of the Morichal path in \\ Yopal, Casanare
}

\author{
Nelly Andrea Bautista R. ${ }^{1}$, Yefer Alexander Nova R. ${ }^{1}$, \\ Martín Orlando Pulido-Medellín. ${ }^{2}$, Roy José Andrade-Becerra. ${ }^{3}$
}

\section{Resumen}

La investigación se llevó a cabo con el objetivo de realizar una determinación serológica de leucosis bovina enzoótica en novillas de levante y vacas adultas. Se recolectaron 100 muestras de sangre de hembras escogidas al azar, pertenecientes a tres fincas del sector La Guafilla, de la vereda Morichal, en Yopal, Casanare, las cuales fueron analizadas para anticuerpos contra el LVB (virus de la Leucosis Viral Bovina); adicionalmente, se obtuvieron 100 muestras de los mismos animales para realización de hemograma, con el fin de observar cambios a nivel sanguíneo de aquellos que resultaran positivos. La técnica serológica empleada fue la prueba de ELISA indirecta. Se realizó un análisis descriptivo tabulando la información con datos de seropositividad y seronegatividad obtenidos de cada animal; los resultados se interpretaron de acuerdo con las variables raza, edad y variaciones del cuadro
\end{abstract}

\begin{abstract}
The research was carried out with the objective of realize a serological determination of enzootic bovine leukosis in raise heifers and adult cows. 100 blood samples were collected of female animals chosen randomly, belonging to 3 farms of Morichal path in Yopal, Casanare, which were analyzed for antibodies against the VBL (Viral Bovine Leukosis); additionally, 100 samples of the same animals were obtained to realize hemogram with the purpose to observe changes in a blood level of those animals who had a positive results. The serological technique used was indirect ELISA test. A descriptive analysis was realized tabulating the information with seropositive and seronegative data obtained of each animal; the results were interpreted according to the variables: breed, age and changes of the hematic count. To determinate the relation between seropositive and each one of the variables was used the Fisher probability test.
\end{abstract}

Médico Veterinario Zootecnista. Universidad Pedagógica y Tecnológica de Colombia. Tunja. e-mail: pequisnabr@hotmail.com.

2 Médico Veterinario Esp. Docente de Medicina Veterinaria y Zootecnia. Universidad Pedagógica y Tecnológica de Colombia. Tunja. e-mail: mopm1@hotmail.com

3 Médico Veterinario. Ph.D. Docente Escuela de Medicina Veterinaria y Zootecnia. Universidad Pedagógica y Tecnológica de Colombia. Tunja. e-mail: royjandrade@yahoo.es 
hemático. Para determinar la relación entre seropositividad y cada una de las variables se utilizó la prueba de Probabilidad de Fisher. Las pruebas arrojaron una seroprevalencia del $15 \%$ para LVB. No se encontraron diferencias significativas de prevalencia asociadas a las variables raza, edad o resultados del hemograma $(p \geq 0.05)$. Se demuestra la presencia del virus de la LBE en La Guafilla. Se confirma la importancia de implementar un programa de control y prevención de la diseminación de la infección, con el fin de evitar las pérdidas económicas asociadas, y, dentro de lo posible, la eliminación de los animales seropositivos para lograr la erradicación de la infección en esta zona del país.

Palabras clave: Leucosis bovina, Linfocitos, Infección bovina. (Fuente: DeCS)
The test showed a seroprevalence of the $15 \%$ for VBL. Significant differences were not found to the variables breed, age or hemogram results $(p \geq 0.05)$. It is demonstrated the presence of the virus of the VBL in La Guafilla. It is confirmed the importance of implementing a control and prevention program for the dissemination of infection, with the purpose to prevent the associated economic losses, and if it is possible, the elimination of seropositive animals to achieve the infection eradication in this zone of the country.

Key words: Enzootic bovine, Lymphocytes, Bovine infection. (Source: DeCS) 


\section{Introducción}

La Leucosis Bovina Enzoótica (LBE) es una enfermedad infecciosa de carácter linfoproliferativo que afecta a las células de la línea "B1"; es causada por el virus de la leucemia bovina (VLB), perteneciente a la familia Retroviridae, es un Deltaretrovirus exógeno. Se considera que sólo se manifiesta clínicamente en un $10 \%$ de los animales infectados, en cuyo caso se caracteriza por presentar una forma tumoral: linfosarcoma, una forma con linfocitosis persistente, presentándose como un estado preleucémico; en los otros casos, los animales tienen anticuerpos sin ninguna manifestación clínica. Esta es una enfermedad cuya distribución es mundial, y tiene una prevalencia variable según la región, explotación y tipo de ganado.

La LBE tiene consecuencias asociadas a problemas reproductivos, disminución en la producción láctea, afecciones digestivas y susceptibilidad a diferentes enfermedades de etiología infecciosa. En condiciones naturales, los animales se pueden contagiar por transmisión horizontal; por malas prácticas de manipulación, como descornar sin desinfectar, palpar con mangas desechables reutilizadas, usar agujas y equipo quirúrgico contaminado; por insectos chupadores de sangre; por transfusiones sanguíneas, $y$, en animales jóvenes, por infección transplacentaria. En un cuadro hemático se puede determinar que este virus afecta principalmente los linfocitos de las células, y por medio de otras pruebas se puede identificar en sangre, leche y fluidos corporales como el semen (Ochoa et al., 2007).

Desde el punto de vista económico, la LBE no solo genera importantes pérdidas en las exportaciones que requieren ganado libre de ella, y en la comercialización de ganado y material genético, sino también por los costos en que se incurre para el diagnóstico, por la muerte prematura de algunos animales como resultado del linfosarcoma, y la pérdida de canales en plantas de beneficio animal.

En la mayoría de las explotaciones del país los productores no llevan a cabo pruebas diagnósticas para detección de enfermedades, ni realizan un diagnóstico inicial, observando signos y síntomas de manera detallada, y cuando la enfermedad se presenta suelen atribuir a esta causas y diagnósticos desconocidos o equivocados, y a la vez se aplica tratamiento y control inadecuados. Sin embargo, algunos estudios realizados en diferentes departamentos de Colombia, en regiones o zonas de estudio muy pequeñas, han involucrado específicamente ganado de leche, a menos que sean bovinos adquiridos en zonas que en algún momento se consideraron endémicas y que no fueron analizados respecto a la presencia del virus (Orjuela et al., 1991).

Por lo anterior, se consideró importante llevar a cabo este estudio en el sector La Guafilla, de la vereda Morichal, en Yopal-Casanare, donde por medio de pruebas diagnósticas realizadas a novillas de levante y vacas adultas divididas en grupos se buscó determinar la prevalencia serológica de la Leucosis Bovina, mediante la prueba de ELISA correlacionada con el Hemograma Bovino. Novillas de levante y vacas adultas, teniendo en cuenta que son pocos los estudios realizados en ganado de carne, y que los realizados indican que el virus de la Leucosis Bovina es principalmente prevalente en el ganado lechero. Con los resultados obtenidos se podrá establecer la presencia o no de la enfermedad en el lugar de estudio, para que se tomen medidas adecuadas de prevención y control del virus de la Leucosis Bovina Enzoótica.

\section{Materiales y Métodos}

Sitio de estudio. El trabajo se desarrolló en el sector La Guafilla, de la vereda Morichal, en YopalCasanare, cuya temperatura promedio oscila entre $24^{\circ} \mathrm{C}$ y $26^{\circ} \mathrm{C}$; el clima está calificado como cálidohúmedo; la humedad relativa permanece con muy baja variación por características de temperatura y precipitaciones. Tiene una extensión de 11.582 ha, representa un $27 \%$ de la extensión de la vereda, cuenta con 10 predios ganaderos -los demás son destinados a otras explotaciones agropecuarias- y tiene 1027 cabezas de ganado. La vereda limita al norte con el casco urbano de Yopal; el caño Agua Verde la separa del corregimiento de Tacarimena; al sur con el río Charte, que lo separa de Aguazul; al occidente la quebrada de Úpamena, que lo separa del corregimiento del Charte, y al oriente los corregimientos de Tacarimena y Tilodiran.

Tipo de estudio y tamaño de la muestra. Por medio del procedimiento estadístico "Determinación de tamaño de muestra para poblaciones finitas" se establecieron 100 animales como muestra representativa para indicar prevalencia de LBE. Se recolectaron muestras de sangre de 100 hembras bovinas de tres fincas del sector de estudio. Según censo Fedegan para vacunación de fiebre aftosa en el ciclo 1 de 2009, el número de cabezas de 
ganado de la vereda Morichal fue de 2809, y el número de cabezas de ganado del sector fue de 1027, obteniendo así un intervalo de confianza del $91.5 \%(0.9150)$.

Selección de la muestra. Se llevó a cabo por el Método Aleatorio Simple de Corte Transversal para seleccionar los animales a muestrear de los listados de cada finca, tomando en cuenta como información complementaria, principalmente, la edad y la raza o cruce para ser correlacionados con los resultados de la prueba de ELISA y los obtenidos de los hemogramas; así, la población de estudio se dividió en grupos: uno de 30 bovinos (novillas de levante), otro de 30 bovinos (vacas secas, horras) y uno de 40 bovinos (vacas lactantes, adultas). Este método estadístico fue útil, dado que todos los miembros de la población tuvieron la oportunidad conocida e igual de ser seleccionados. (Ross, 2000; Charles, 2006).

Obtención del suero y procesamiento de las muestras. La toma de muestras de sangre se realizó en la vena coccígea media, con agujas de calibre 16 o 18, con longitud de 1.5 pulgadas (una aguja por animal, y utilizada para tomar la muestra para la prueba de ELISA y el cuadro hemático) (De la Sota, 2004). Previamente se realizó limpieza del sitio de punción con un producto yodado (Parra, 2007), luego se introdujo una aguja en la vena y se recogió la sangre en un tubo tapa roja y en otro de tapa lila (con anticoagulante); se tomaron $5 \mathrm{~mL}$ de sangre por animal por tubo, aproximadamente (Cotrino, 2005). Los animales muestreados fueron hembras bovinas lactantes de 2 años de edad, secas de 2 años de edad y novillas de levante de 1 a 2.5 años de edad de sistemas de producción de carne y doble propósito. El procesamiento de las muestras se realizó en la Fundación Colombiana para el Estudio de Parásitos, FUNCEP, con la colaboración del Dr. José Luis Azumendi, en la ciudad de Bogotá, y los sueros fueron procesados mediante la técnica de ELISA, utilizando el Kit para la Detección de Anticuerpos frente al Virus de la Leucosis Bovina (BLV) CHEKIT* Leucose Serum de laboratorios IDEXX. Este kit proporciona un método rápido, simple, sensible y específico en muestras individuales de suero o plasma y en mezclas de hasta 10 sueros o plasmas de bovino. Los resultados arrojados por esta técnica se relacionaron con los cambios observados en el hemograma bovino. Las muestras para hemogramas fueron procesadas en el Laboratorio Clínico Veterinario de la Clínica de Grandes y Pequeños Animales de la Uptc.
Análisis estadístico. Se aplicó la Prueba de Probabilidad de Fisher, haciendo un análisis estadístico de las variables establecidas y determinando si representan un factor en la presentación de la enfermedad. Hipótesis nulas y alternas para las pruebas de ELISA en los tres grupos: Cuando el valor $p<0.05$, la hipótesis se considera alterna, y cuando $p \geq 0.05$, la hipótesis es nula. Por ejemplo: las hipótesis nulas $(\mathrm{Ho})$ establecen iguales proporciones de casos positivos y negativos de la prueba de ELISA en cada clase de la variable, y las hipótesis alternas establecen que hay una proporción menor en alguna de las dos clases de la variable.

\section{Resultados y Discusión}

De las 100 muestras procesadas, la seroprevalencia total fue de un $15 \%$ (15 animales) de positividad en la prueba de ELISA para LBE, y un $85 \%$ de negatividad. En la figura 1 se muestra que de este $15 \%$, el $60 \%$ corresponde a la prevalencia en la finca Santa Catalina; el 33.3\%, a la finca El Paraíso, y el $6.6 \%$, a la finca El Carmen.

La mayor parte de los estudios realizados sobre LBE se han llevado a cabo en ganado lechero, y demuestran que este tipo de ganado presenta mayor prevalencia de la enfermedad, según Alayon (2004), Parra (2007) y Barón y Pire (2006). Para el caso de este estudio, la prevalencia encontrada, del $15 \%$, concuerda con lo dicho por Schwartz y Levy (1994), que los estudios realizados en ganado de carne indican una prevalencia baja.

Según Rebhun (1995), en la ganadería de leche es mayor la incidencia de esta enfermedad, dados los factores de riesgo, que están relacionados en gran parte con las prácticas de manejo en las diferentes regiones, o según el ganado que se está trabajando, en lo que se refiere a la raza y tipo de producción. Se deben tener en cuenta los factores que contribuyen a la presentación o no de la enfermedad, dependiendo de las condiciones en que se realicen dichas prácticas como: frecuencia de palpaciones, procesos de desparasitación, exposición a tatuadoras, guayas para descorne, material para cirugía y agujas reutilizadas, entre otros procesos que en ocasiones no son manejados de manera adecuada, representando un factor de riesgo y fuente de transmisión de la enfermedad; esto se refiere a que en ganado de clima caliente, por características de raza, costumbres de la región y condiciones geográficas, no son muy frecuentes estos procedimientos, comparados con el manejo 
que se le da al ganado de clima frío; además, es importante tener en cuenta que el ganado aumenta los niveles de estrés al momento de ser sometido a cualquier tipo de procedimiento de los ya mencionados; como lo plantea Rosciani (1997), las hembras sometidas a factores estresantes están expuestas a padecer formas más severas de la enfermedad.

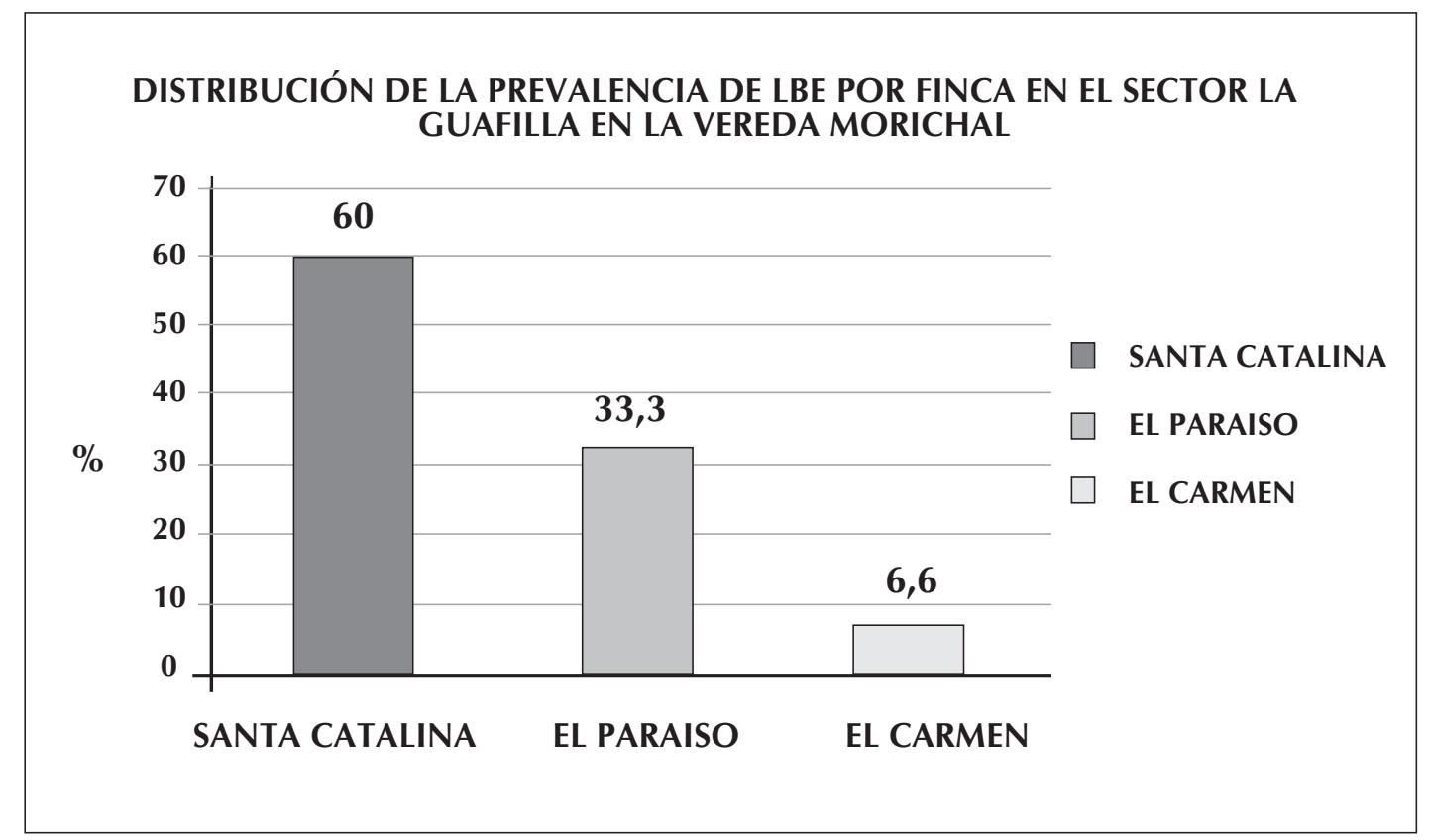

Figura 1. Prevalencia de LBE en la vereda Morichal

Según Castelli y Vanzini (2001), el tipo de explotación ganadera influye en la prevalencia de la enfermedad; cuando una ganadería es intensiva, los animales están expuestos a hacinamiento, a mayor contacto $y$, a la vez, a un aumento en la manipulación por los operarios, lo que es frecuente en regiones de climas fríos; al contrario, en las ganaderías extensivas, características de clima cálido, como es el caso de este estudio, el ganado se encuentra en grandes extensiones, lo que disminuye el contacto directo y el manejo de los operarios es menor.
Al realizar el examen previo a la toma de muestras no se encontró ningún animal con signos o síntomas que indicaran presencia de la enfermedad. Según Almansa (2000), los animales infectados pueden mantenerse clínicamente sanos; en la mayoría de los casos la enfermedad es subclínica, por lo que su diagnóstico se dificulta.

Del $15 \%$ de prevalencia de LBE en la vereda Morichal, $60 \%$ corresponde al grupo de vacas adultas (lactantes); 20\%, al grupo de vacas horras (secas), y $20 \%$, al grupo de novillas de levante. 


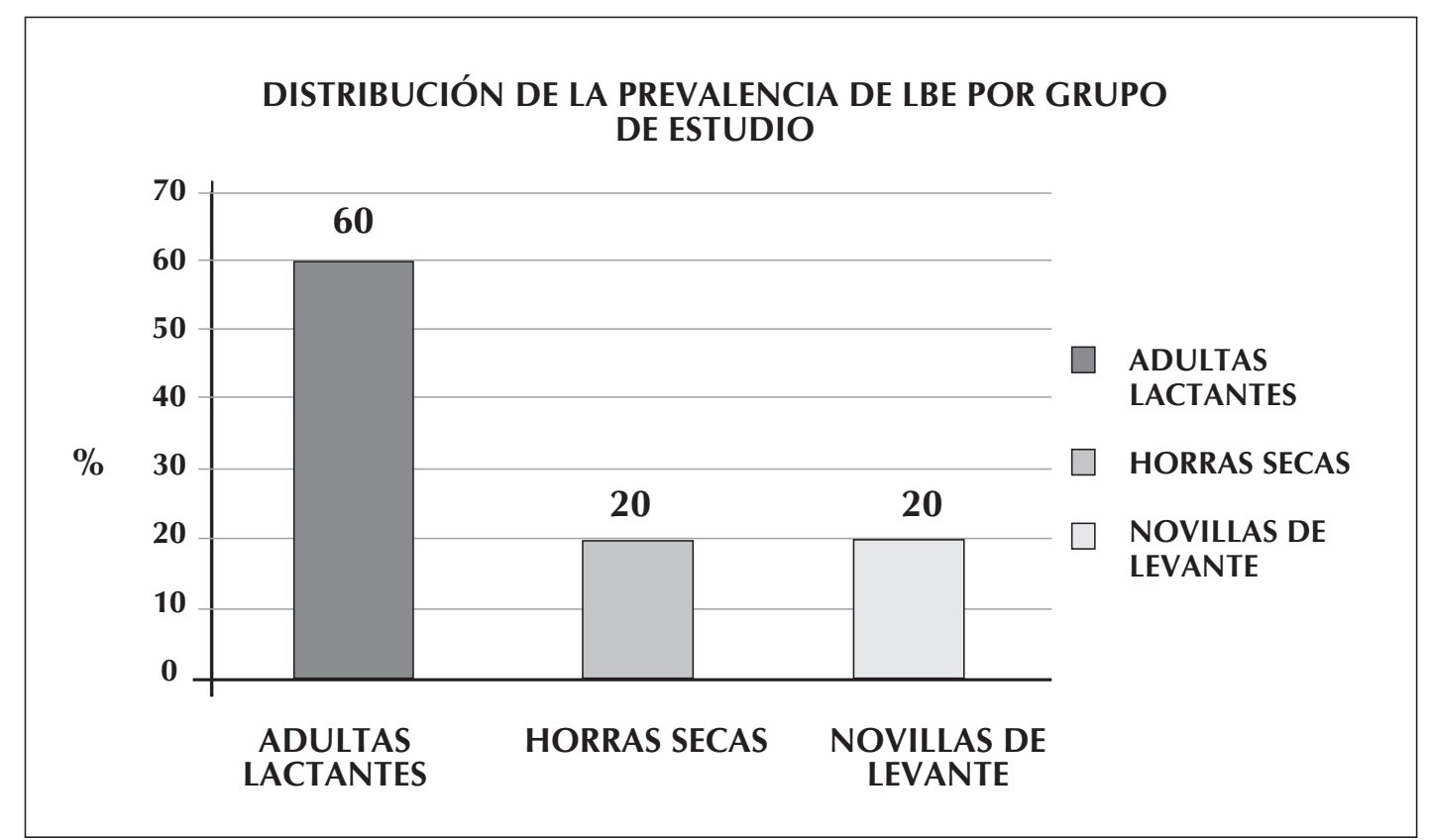

Figura 2. Prevalencia de LBE por grupo de estudio en la vereda Morichal.

Según Alayon (2004) y Resoagli et al. (1991), la enfermedad se presenta con mayor frecuencia en animales adultos, que en algunos casos la pueden adquirir desde jóvenes pero sólo se manifiesta en la edad adulta. Lo anterior concuerda con los resultados obtenidos en nuestro estudio, donde la prevalencia fue del $80 \%$ en vacas adultas (lactantes y horras) y del $20 \%$ en novillas de levante; esto coincidió en las tres fincas estudiadas, donde la mayor prevalencia fue en vacas adultas. Estos animales representan un riesgo para los sanos, ya que son diversas las formas de transmisión.

De los tres grupos muestreados, el de la finca Santa Catalina presentó una prevalencia del $22.5 \%$, siendo la finca con mayor número de animales positivos; estos resultados podrían estar relacionados con el grado de manipulación que allí se realiza al ganado. En la finca El Paraíso se obtuvo una prevalencia del $16.6 \%$, que podría deberse a que las prácticas de manejo del ganado se realizan esporádicamente. $\mathrm{Y}$ finalmente el grupo de estudio de la finca El Carmen presentó una prevalencia del $3.33 \%$, que podría atribuirse a la mínima manipulación dada al ganado, ya que según el propietario esta finca no cuenta con encargados de tiempo completo, sino que hacen visitas semanales para verificar número de cabezas de ganado; otras prácticas o procedimientos nunca se llevan a cabo, o casi nunca, solo según la necesidad del caso.

\section{Conclusiones}

La determinación serológica de Leucosis Bovina Enzoótica en novillas de levante y vacas en producción del sector La Guafilla, de la Vereda Morichal, de Yopal, Casanare, fue del 15\% de seropositividad según la prueba de ELISA; al correlacionar estos resultados con los cuadros hemáticos, tanto animales positivos como negativos presentaron variaciones similares a nivel serológico, y ningún signo o síntoma que indicara presencia de la enfermedad. Según estudios realizados, hay animales que resultan serológicamente positivos, pero clínicamente sanos y sin modificaciones en su hemograma. Lo mismo sucedió con las variables edad y raza, ya que para este estudio no son factores determinantes para la presentación de LBE, pues se puede presentar en cualquier edad o raza; de la misma manera, en cuanto al cuadro hemático, 
los valores tanto normales como menores y mayores a los normales de eritrocitos, leucocitos, neutrófilos segmentados, neutrófilos bandas y linfocitos no están relacionados directamente con la seropositividad o seronegatividad dada por la prueba de ELISA.

Tanto animales positivos como negativos se encontraban en el mismo entorno y con las mismas condiciones de mantenimiento, por lo que se puede decir que los factores de riesgo que predisponen a la presencia de la enfermedad pueden estar dados principalmente por el manejo y las prácticas que se llevan a cabo en cada una de las fincas, siendo éste un aspecto que hay que tener en cuenta para prevenir la presentación de la enfermedad y controlar su propagación, implementado buenas prácticas ganaderas no slo en el lugar de estudio, sino en toda la región.

\section{Literatura citada}

Almansa, J. (2000). Carta Fedegan. Manejo Integral de Plagas y Enfermedades en Explotaciones Ganaderas Federación Colombiana de Ganaderos. Leucosis Enzoótica Bovina, una nueva visión sobre la enfermedad.

Barón, H., Pire, A. (2006). Seroprevalencia de Leucosis Enzoótica Bovina en el municipio de Sotaquirá durante el año 2006. Uniboyacá. Facultad de Ciencias de la Salud. Bacteriología y Laboratorio Clínico 2006.

Castelli, M. E.; Vanzini, V. (2001). Prevalencia de anticuerpos contra la rinotraqueitis y la leucosis viral bovina en vaquillonas Holando Argentino preservicio del centro de Santa Fe y este de Córdoba. Evolución de la infección de Leucosis enzoótica bovina. Anales del $24^{\circ}$ Congreso Argentino de Producción Animal de Ciencias Veterinarias. Buenos Aires, p. 49.

Charles, W., Joseph, F., Hair, C., McDaniel, D. (2006). Marketing. Edition: 8. Publicado por Cengage Learning Editores. URL disponible en http://books.google.com. co/books?id= K9Hg3Rpf054C http:// www.revistaciencias.com/publicaciones/ EEZZpAIVFpLeJclctD.php. [Fecha de acceso 17 de marzo de 2012].

Cotrino, V. (2005). Instructivo de toma, almacenamiento y transporte de muestras para diagnóstico veterinario. LMV. Ltda.

Ochoa-Cruz, A., Uribe, A., Gutiérrez, M. (2007). Estudio del potencial zoonótico del virus de la Leucosis bovina y su presencia en casos de cáncer de seno. Departamento de Microbiología, Facultad de Ciencias, Facultad de Medicina, Pontificia Universidad Javeriana. Revista de la Facultad de Ciencias. Vol. 11, N. ${ }^{\circ}$ 2, 31-40. Bogotá. URL disponible en: $\quad$ www.javeriana.edu.co/universitas scientiarum/universitas docs/vol11 $2 \bar{l}$ ESTUDIO POTENCIAL.pdf. [Fecha de accēso 15 de maržo de 2012].

Orjuela, J., Navarrete, M., Betancourt, L. (1991). Salud y productividad en bovinos de la costa norte de Colombia. ICA. URL disponible en: http://www.fao.org/ag/aga/agap/fig/feedback/ war/u9900bOg/htm. [Fecha de acceso 21 de marzo de 2012].

Parra-Vargas, U. A. (2007). Seroprevalencia de la leucosis enzoótica bovina en la Granja Experimental Tunguavita. Universidad Pedagógica y Tecnológica de Colombia. Facultad de Ciencias Agropecuarias. Escuela de Medicina Veterinaria y Zootecnia. Tunja. Colombia.

Rebhun, W. C. (1995). Enfermedades del ganado vacuno lechero. Infección con el virus de la leucemia bovina (Leucosis) (Linfosarcoma bovino). España: Acribia.

Resoagli, J. P., Jacobo, R. A., Storani, C. A., Cipolini, M. F., Stamatti, G. M., Deco, M., Alfonzo, D. (1991). Seroprevalencia de la leucosis enzoótica bovina en rodeos lecheros de la región noroeste de la Provincia de Corrientes, Argentina. Cátedra de Enfermedades Infecciosas, Facultad de Ciencias Veterinarias, UNNE.

Rosciani, A. S., Merlo, W. A., Montenegro, M. A., Pérez-Gianeselli, M. R., Borda, J. T., Lertora, J., Macció, O.A., Sánchez-Negrette, M. (1997). Determinación de animales seropositivos a leucosis enzoótica bovina en establecimientos del NEA. Anales de la Reunión de Comunicaciones Científicas y Tecnológicas de la SGCYT. UNNE, Corrientes, Argentina, p. 123-126.

Ross, S. (2000). Probabilidad y estadística para ingenieros. Segunda Edición. McGraw Hill.

Schwartz, I., Levy, D. (1994). Pathobiology of Leucemia Virus. Vet Res., 1994; 25, 521-536.

Fecha de Recepción: 5 de abril de 2012

Fecha de Aceptación: 30 de abril de 2013 